$\underline{\mathbf{P}-4}$

\title{
Chemical Constituents and Their Biological Activities of Artocarpus Communis
}

\author{
Clifford Junaidi Kutoi ${ }^{1}$, Khong Heng Yen ${ }^{1, *}$, Yana Maolana $\operatorname{Syah}^{2}$ and Euis H. Hakim ${ }^{2}$ \\ ${ }^{1}$ School of Chemistry and Environmental Studies, Faculty of Applied Sciences, University Teknologi MARA, 94300 Kota \\ Samarahan, Sarawak, Malaysia; ${ }^{2}$ Natural Products Chemistry Group, Faculty of Mathematics and Natural Sciences, \\ Institut Teknologi Bandung, Jalan Ganesha 10, Bandung 40132, Indonesia; E-mail: khonghy@sarawak.uitm.edu.my
}

Artocarpus (Moraceae) comprises about 50-60 species and distributed throughout South and Southeast Asia, New Guinea and Southern Pacific region. A. communis is locally known as a "Sukun". Artocarpus species are well known for its medicinal purposes including used for the treatment of inflammation, ulcers, diarrhea and malaria fever. Previous studies reported that this plant exhibited bioactive compounds such as flavonoids, stilbenoids and arylbenzofurons which respond to the pharmacological activities involving the anti-malaria, anti-microbial, anti-inflammatory and cytotoxic against HL 60 cells line, MCF 7 cells line, P388 cells line, HT 29 and others. The isolation of methanolic leaves extract of A. communis was successfully led to three phenolic compounds, namely 1-(2,4-Dihydroxyphenyl)-3-[8-hydroxy-2-methyl-2-(4-methyl-3-pentenyl)-2H-1-benzopyran-5yl]-1-propanone (1), 8-(3,6-Dimethyl-2-heptenyl)-4',5,7-trihydroxyflavanone (2), 1-(2,4-Dihydroxyphenyl)-3-[2-(3,7-dimethyl2,6-octadienyl)-3,4-dihydroxyphenyl]-1-propanone (3) and squalene (4). Compound 4 was reported for the first time from this species. On biological properties evaluation, compounds $\mathbf{1}$ and $\mathbf{3}$ showed strong cytotoxicity against Hep-G2 cell lines while compounds 1-3 demonstrated strong inhibition against Staphylococcus aureus, Streptococcus pyogenes, Pseudomonas aeruginos, Escherichia coli and Clostridium difficile based on the minimum inhibitory concentration (MIC) assays.

Keywords: Artocarpus communis, cytotoxic, Hep-G2 cell lines, anti-microbial. 